\title{
Strangers in a Strange Land
}

\section{Primary Care Physicians in Academic Medical Centers}

C areer-satisfaction surveys are a peculiar form of selfobsession. They usually tell us more about the biases and needs of the surveyors than about truths related to the work. A study in this issue is an exception. ${ }^{1}$ Through fairly detailed telephone interviews of academic physicians in family medicine and general internal medicine as well as of second-year residents and fourth-year medical students intending to pursue careers in those disciplines, Zinn and his colleagues create a picture of academic primary care that is disturbing, not only for those engaged in it but even more so for the academic medical centers in which the respondents work. But more about that in a moment-first, a bit of self-obsession.

As judged by the results of this study, academic family medicine and general internal medicine physicians appear to live in entirely different worlds, with very different views of their roles as well as their surroundings. Their perceptions of the value of their clinical and academic activities differ so much that they seem to be strangers to one another despite the seeming similarity of what they do and where they do it. Family medicine physicians are, in general, more assertive about their clinical roles, more enthusiastic about their educational responsibilities, and more excited about their research contributions than their general internal medicine counterparts. Interestingly, both groups enjoy roughly equal, and relatively high satisfaction from their work, suggesting that either family medicine physicians are inappropriately optimistic about the quality and quantity of their contributions, or general internal medicine physicians suffer from excessively low expectations, which are unfortunately matched by their limited contributions as academic primary care physicians.

More specific questions come to mind. Are family medicine physicians inappropriate in their enthusiasm for caring for complex patients? Do they suffer from hubris in their low opinion of the complexity of some specialty care? Why do general internal medicine academic physicians think so little of what they do that they denigrate its educational value? Do they appropriately discount their own research when it looks so drab compared with the molecular miracles spun out by their high-technology research colleagues? The study cannot answer these questions, but the accuracy of the study's assessment of the marked discrepancy in self-concept between general internal medicine and family medicine physicians is confirmed by the way these attitudes are amplified in their respective trainees. Residents and students intending to become general internists reported far less enthusiasm for the careers of their mentors, to the extent they even had mentors and role models, than residents and students intending to become family medicine physicians, who reported relatively high satisfaction with and much greater availability of such role models. Given the replication of these attitudes in the next generation, there is a high likelihood these differences will be perpetuated for the foreseeable future unless there are drastic changes in the values and vision of academic medical centers. And that brings me to the more significant implications of this study.

These data are a subset of a larger study of specialty attitudes toward primary care, the results of which received wide publicity and comment for their portrayal of a negative and hostile climate for primary care in academic medical centers. ${ }^{2}$ This picture, which fits with my observations over the past 25 years of living and working in such places, has always puzzled me. The central, defining philosophy of the academic medical center is claimed to be clinical and academic excellence, using rigorous, peerreviewed methods to practice, teach, and study the highest quality of medical practice. This philosophy should be equally applicable to the problems of population-based primary care as to those of the Human Genome Project, yet academic medical centers have created a win-lose, zero-sum, either-or dichotomy between these two worlds, with tertiary care, specialism, and molecular biology the clear winners. Such a selective application of these general principles of academic excellence is presumably due to a historical accident in the way medical research is funded, a version of Willie Sutton's explanation that the reason he robbed banks is because "that's where the money is." However, perpetuating this false dichotomy has led to a worrisome marginalization of academic medical centers in society, with most of them struggling to define their relevance to population-based health care delivery needs and to be competitive with nonacademic health care systems. The anticipated demise of some academic medical centers over the next several years and the wrenching reorganization of the rest, which already is under way, result from an excessive obsession with a reductionistic approach to health care delivery, teaching, and research. ${ }^{3,4}$ So, with appropriate apologies to the Book of Genesis, not only are family medicine and general internal medicine physicians strangers to one another, they also are strangers in a strange land, a land that should value what these physicians do, but apparently does not.

The respondents in the study by Zinn and colleagues appear to have responded to this situation in diametrically opposed ways. The family medicine physicians have maintained their enthusiasm for what they do through separate department status, but at the cost of physical, administrative, and philosophical isolation from the academic medical center's day-to-day life, and a countercultural approach that often results in being marginalized. The general internal medicine physicians appear to hold 
their professional role in fairly low regard, as do their students and residents, yet are as satisfied with their work as are their family medicine counterparts, presumably because they are part of a larger department of internal medicine that is the flagship of most academic medical center fleets and provides a supportive and esteem-enhancing environment within which to work.

In my role as a member of the National Advisory Committee of the Robert Wood Johnson Generalist Faculty Scholars Program, I have observed these differences in program applicants, who represent "the best and the brightest" of academic primary care physicians. Family medicine faculty physicians seem to ask more interesting research questions that deal with important populationbased primary care problems (my bias, admittedly, but one shared by many of my academic general internal medicine friends), but they are often removed from the core research infrastructure support of their sponsoring academic medical center, have weak methodologic training and skills, and have difficulty managing their clinical and educational commitments. General internal medicine faculty physician applicants are usually part of a larger internal medicine research enterprise, with strong mentoring and infrastructure that supports them in their full devotion to research, but their research questions are frequently derivative to, and their clinical practice somewhat removed from, "real" population-based medical care. To my mind, academic primary care would benefit from taking the "best of both worlds" of "the best and the brightest," some sort of hybrid that combines the family medicine enthusiasm for practicing, teaching, and conducting research in community-based patient populations with the methodologic rigor, academic credibility, and support of general internal medicine.

So, the real importance of the study by Zinn and colleagues is what it says about the future of academic med- ical centers, and what academic medical centers need to do to have a future. They run the risk of becoming marginalized because primary care is marginalized. The family medicine physicians who are enthusiastic about primary care work on the fringes of the academic medical center's power structure, and the general internal medicine physicians who are more credible and centrally placed have a low self-image as primary care physicians. Even worse, these attitudes are being accurately replicated in subsequent generations of academic primary care physicians. All of this is occurring in an academic medical center with a highly skewed value system that is unsupportable on both a philosophical and a financial basis. The academic primary care physician is like the canary in the coal mine, whose continued good health is a measure of the quality of the air everyone else breathes. Wise academic medical center leaders will take a hard look at their institutions' value systems, and endeavor to enhance the work and careers of the physicians who hold the academic medical center's very salvation in their hands-family medicine and general internal medicine academic physicians committed to population-based primary care clinical and academic programs.-THomas $\mathbf{L}$. Schwenk, MD, Department of Family Medicine, University of Michigan Medical Center, Ann Arbor.

\section{REFERENCES}

1. Zinn WM, Block SD, Clark-Chiarelli N. Enthusiasm for primary care: comparing family medicine and general internal medicine. J Gen Intern Med. 1998;13:186-94.

2. Block SD, Clark-Chiarelli N, Peters AS, Singer JD. A chilly climate for primary care. JAMA. 1996;276:677-82.

3. Iglehart JK. Rapid changes for academic medical centers. 1. N Engl J Med. 1994;331(20):1391-5.

4. Iglehart JK. Rapid changes for academic medical centers. 2. N Engl J Med. 1995;332(6):407-11. 